\title{
Time, culture and psychiatric diagnosis
}

\section{Aleksandar Janca*}

Address: University of Western Australia, School of Psychiatry and Clinical Neurosciences, Perth, Australia

* Corresponding author

from International Society on Brain and Behaviour: 2nd International Congress on Brain and Behaviour Thessaloniki, Greece. 17-20 November 2005

Published: 28 February 2006

Annals of General Psychiatry 2006, 5(SuppI I):S66 doi:10.1 186/1744-859X-5-SI-S66

Lecture: Perception of time differs across cultures and settings. Western cultures perceive time as being "linear" (i.e., past, present and future), one-directional, longitudinal, durational and chronological. Such a concept of "linear time" is imbedded in Western psychiatry in the context of which mental disorders are defined in terms of their onset, duration, frequency and clustering of symptoms. Linear concept of time is used to classify mental disorders into acute, chronic, episodic, recurrent etc. Some other cultures including many groups of indigenous people do not perceive time as an exclusively "linear" category and often place events in a "circular" pattern of time, according to which an individual person is in the centre of concentric "time circles". All experiences and events (including symptoms and signs of mental illness) are placed in time according to their relative importance for the individual and his/her respective community (i.e. more important events are perceived as being "closer in time". In our view and experience, these cross-cultural differences in the perception of time contribute to the limited applicability of currently used diagnostic systems and assessment instruments in psychiatry and create numerous difficulties in providing culturally appropriate mental health care in different parts of the world.

\section{References}

I. Janca A, Bullen C: The Aboriginal concept of time and its mental health implications. Australasian Psychiatry 2003, I I:S40-S44. 